\title{
Citologia de impressão no diagnóstico de infecção corneana por Acanthamoeba: relato de caso
}

\author{
Diagnosis of Acanthamoeba corneal Infection by impression cytology: \\ case report
}

\author{
Jeison de Nadai Barros ${ }^{1}$ \\ Vera Lucia Degaspare Mascaro ${ }^{2}$ \\ Marcia Lowen $^{3}$ \\ Maria Cristina Martins ${ }^{4}$ \\ AnnetteForonda ${ }^{5}$
}

Trabalho realizada no Departamento de Oftalmologia da Universidade Federal de São Paulo - UNIFESP - São Paulo (SP) - Brasil.

${ }^{1}$ Tecnólogo Oftálmico, Pós-graduando do Departamento de Oftalmologia da Universidade Federal de São Paulo - UNIFESP - São Paulo (SP) - Brasil.

${ }^{2}$ Médica colaboradora do Laboratório de Doenças Externas Oculares, Chefe de ambulatório de Patologia Externa e Córnea, e Pós-graduanda do Departamento de Oftalmologia da UNIFESP - São Paulo (SP) - Brasil.

${ }^{3}$ Doutora em Patologia, Colaboradora do Laboratório de Patologia Ocular da UNIFESP - São Paulo (SP) - Brasil.

${ }^{4}$ Doutora em Oftalmologia, Professora afiliada e Chefe do Setor de Patologia Ocular do Departamento de Oftalmologia da UNIFESP - São Paulo (SP) - Brasil.

${ }_{5}^{5}$ Professora Doutora do Instituto de Ciências Biomédicas da Universidade de São Paulo - USP - São Paulo (SP) Brasil. Colaboradora do Laboratório de Doenças Externas Oculares da UNIFESP - São Paulo (SP) - Brasil.

Endereço para correspondência: Jeison de Nadai Barros. Al. Gabriel Monteiro da Silva, 1000 - São Paulo (SP) CEP 01442-000

E-mail: jbarros@oftalmo.epm.br

Recebido para publicação em 30.11.2005

Última versão recebida em 28.06.2006

Aprovação em 11.07.2006

\begin{tabular}{|l|}
\hline RESUMO \\
\hline Relatamos três casos de infecção corneana por Acanthamoeba sp em que \\
foi possível detectar cistos do microorganismo com a técnica de citologia \\
de impressão. Três pacientes encaminhados ao Laboratório de Doenças \\
Externas Oculares em 2004 com alterações superficiais da córnea foram \\
submetidos ao exame de citologia de impressão para investigação da \\
presença de cistos de Acanthamoeba sp. Duas amostras foram obtidas \\
da córnea de cada paciente coradas com PAS, hematoxilina e Papanico- \\
laou. Investigação microbiológica de rotina e cultura também foram \\
realizadas após raspado da córnea. O cultivo das amostras e a citologia \\
de impressão foram positivas para Acanthamoeba sp em todos os \\
pacientes, ao passo que os raspados corados com Giemsa foram positi- \\
vos em dois casos. A citologia de impressão revelou cistos de Acantha- \\
moeba sp entre feixe de células epiteliais corneanas e como células \\
isoladas. Foram observados cistos no epitélio de um dos pacientes com \\
a citologia de impressão após três meses de tratamento, enquanto o \\
raspado foi negativo. No exame anatomopatológico observaram-se cis- \\
tos no epitélio e estroma de uma córnea receptora de um dos pacientes \\
após transplante. Neste estudo, a citologia de impressão detectou com \\
sucesso cistos de Acanthamoeba sp em pacientes com acometimento \\
epitelial. Por tratar-se de método não invasivo, a técnica pode ser usada \\
para facilitaro diagnóstico mais precoce da infecção por Acanthamoeba, \\
sendo útil também no acompanhamento do tratamento da doença.
\end{tabular}

Descritores: Ceratite por Acanthamoeba/diagnóstico; Doenças da córnea; Técnicas citológicas; Técnicas de diagnóstico oftalmológico; Ceratite/diagnóstico; Relatos de casos [Tipo de publicação]

\section{INTRODUÇÃO}

Protozoários de vida livre do gênero Acanthamoeba, encontrados nas formas trofozoítica e cística, podem causar ceratite infecciosa crônica ${ }^{(1)}$. A doença pode ser grave, afeta a integridade da córnea e conseqüentemente a acuidade visual, podendo estar associada a traumas da córnea e à água contaminada, especialmente em usuários de lentes de contato. Hipóxia e microtraumas no epitélio da córnea induzidos pela lente poderiam facilitar a invasão do tecido da córnea por Acanthamoeba sp, assim como a assepsia inadequada das lentes favorece contaminações bacterianas, fúngicas e por ameba, criando um ambiente favorável ao crescimento dos microrganis$\operatorname{mos}^{(2)}$. O diagnóstico precoce é importante para o início do tratamento e para um melhor prognóstico visual. A ceratite por Acanthamoeba é de 
difícil tratamento, uma vez que a dupla parede do cisto protege o organismo, sendo capaz de resistir a congelação, dessecação, e penetração de drogas ${ }^{(3)}$. Várias dificuldades são encontradas para o diagnóstico devido as suas diferentes formas de apresentação biomicroscópicas e evolução. Os primeiros sinais desta ceratite são inespecíficos, podendo ser confundidos com outras condições, como na infecção provocada pelo herpes simples ${ }^{(4)}$. Devido à sua habilidade de encistar-se, Acanthamoeba sp torna-se mais resistente ao tratamento, podendo invadir profundamente a córnea, além de outros segmentos oculares, como a câmara anterior e esclera. O transplante de córnea pode ser indicado como tratamento nos olhos com evolução inadequada com risco à integridade do órgão( ${ }^{(5)}$.

O método padrão para a identificação de Acanthamoeba sp é a cultura em meios específicos, tal como ágar não nutriente com E.coli/Enterobacter aerogenes. Os trofozoítos e os cistos podem ser encontrados nos raspados da córnea corados com Gram e Giemsa ou com outros métodos para diagnóstico, como "calcofluor white" e imunofluorescência indireta. Essas colorações requerem uso de métodos invasivos para obtenção de tecido da córnea, seja por raspado ou por bióp$\operatorname{sia}^{(6)}$. No entanto, a citologia de impressão, método não invasivo para avaliação da superfície ocular que emprega uso de papel filtro de ésteres de celulose, foi recentemente relatada como útil na detecção de cistos no epitélio da córnea de pacientes com diagnóstico clínico de ceratite superficial por Acanthamoeba sp confirmada por cultura ${ }^{(7)}$. A citologia de impressão é usada como exame complementar de rotina em diversos diagnósticos como: deficiência de células germinativas no limbo ${ }^{(8)}$, metaplasia escamosa com perda de células caliciformes conjuntivais $^{(9)}$, lesões neoplásicas da superfície ocular, entre outras ${ }^{(10)}$.

Neste artigo relatam-se três casos de ceratite por Acanthamoeba sp com cistos detectados na córnea pela citologia de impressão (CI), pela citologia esfoliativa, pelo cultivo das amostras e identificação do microrganismo e, em um dos casos, com exame anatomopatológico.

\section{MÉTODOS}

Foram encaminhados ao Laboratório de Doenças Externas Oculares para exame de CI três pacientes com alterações na superfície da córnea e suspeita clínica de ceratite por Acanthamoeba sp, em 2004, com o objetivo de investigar a presença de cistos deste protozoário. Todos os indivíduos eram usuários de lente de contato descartável e negavam história de trauma ocular. Dois pacientes já haviam feito tratamento tópico sem melhora, no qual o primeiro diagnóstico clínico havia sido ceratite por herpes.

\section{Citologia de impressão}

Duas amostras foram obtidas da córnea de cada paciente. Foi usado o papel filtro de acetato de celulose Millipore
HAWP304F0 com 0,45 micra de poro. Após anestesia tópica, o papel foi aplicado sobre a área afetada da córnea, pressionado por alguns segundos, removido por "peeling" e imediatamente fixado em solução mista de ácido acético glacial, formaldeído a 37\% e álcool etílico 70\% na proporção 1:1:20. Após 10 minutos foi corado conforme técnica padronizada já descrita anteriormente $^{(9)}$, que inclui: ácido periódico de Schiff (PAS), hematoxilina e Papanicolaou modificado. A amostra foi observada sob microscopia óptica. A análise consistiu na observação das células epiteliais, células inflamatórias, muco e presença de estruturas com dupla parede sugestiva de cisto, isoladas ou agrupadas.

Investigação microbiológica de rotina (citologia esfoliativa com coloração de Giemsa, bacterioscopia, antibiograma) e cultivo das amostras também foram realizados após raspado da córnea em todos os pacientes. Em um caso foi realizada nova colheita com amostras para todos os exames laboratoriais após três meses de tratamento devido a melhora parcial dos sinais clínicos e dos sintomas.

O exame anatomopatológico foi realizado no botão da córnea de um dos pacientes, o qual foi submetido a transplante de córnea na vigência do quadro infeccioso.

\section{RESULTADOS}

O cultivo das amostras e a CI foram positivas para Acanthamoeba $\mathrm{sp}$ em todos os pacientes, enquanto que os raspados corados com Giemsa foram positivos em dois casos. A CI revelou cistos de Acanthamoeba sp entre feixe de células epiteliais corneanas e como células isoladas. Os microrganismos foram facilmente reconhecidos devido à morfologia peculiar de cistos com dupla parede (Figura 1).

Foram encontrados cistos no epitélio de um dos pacientes com a CI após três meses de tratamento, enquanto o raspado foi negativo.

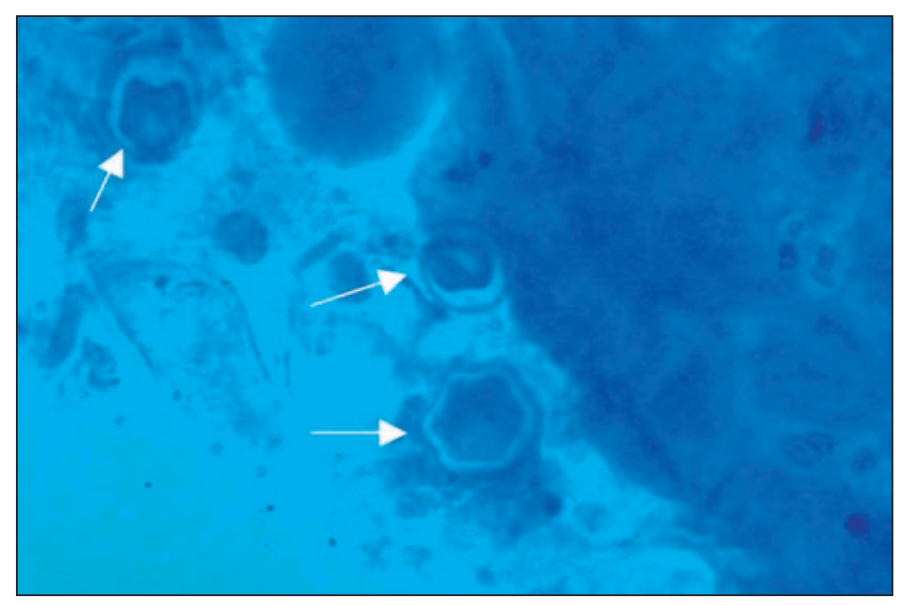

Figura 1 - Citologia de impressão revela cistos de Acanthamoeba sp na superfície da córnea com comprometimento do epitélio de usuário de lente de contato gelatinosa (HE, PAS, Papanicolaou 400x) 
O exame anatomopatológico exibiu cistos no epitélio e no estroma do botão da córnea obtido após transplante no único paciente submetido à cirurgia.

\section{DISCUSSÃO}

O diagnóstico e tratamento da ceratite por Acanthamoeba representa um desafio aos oftalmologistas ${ }^{(11)}$. Não há drogas específicas aprovadas para tratar esse processo infeccioso. Não há métodos padronizados para se testar a sensibilidade de Acanthamoeba sp às várias medicações, nem métodos para se avaliar a erradicação do parasita, uma vez que a recorrência pode ocorrer. Estudos recentes sugerem que a frequiência da infecção por Acanthamoeba seja igual a 1,2 infectados por ano em cada milhão de adultos no país de Gales e na Inglaterra e de 0,2 a 1 indivíduo para cada 10.000 usuários de lentes de contato por ano ${ }^{(12)}$. A suspeita diagnóstica precoce determina o melhor prognóstico e depende do reconhecimento de sinais clínicos não específicos. É nesse momento que o exame laboratorial pode auxiliar a complementar informações para o diagnóstico correto da ceratite por Acanthamoeba.

As manifestações clínicas mais características como os infiltrados em anel são vistos nas fases mais avançadas da doença. Os casos possíveis para o diagnóstico citológico são aqueles precoces, ainda sem tratamento, porque após a terapia antiamébica os organismos podem encistar-se e migrar para o estroma profundo.

Recentemente foi relatado o uso da microscopia confocal na detecção de cistos de Acanthamoeba sp, até mesmo com auxílio da técnica de $\mathrm{PCR}^{(13-14)}$. Embora seja um método não invasivo, o alto custo do equipamento é um fator que limita o uso.

A CI tem menor custo, é um método não invasivo, bem tolerado pelos pacientes, e não requer raspado da córnea. Sua utilização para detecção de $\operatorname{cistos}^{(6)}$ coincide com a técnica previamente descrita no presente estudo, que inclui avaliação citológica com Papanicolaou ${ }^{(9)}$. Esta coloração também pode ser empregada para investigar cistos de Acanthamoeba sp em amostras obtidas por raspado da córnea para a realização de citologia esfoliativa $^{(15)}$. Anteriormente, a CI havia sido descrita como um método para obtenção de amostras do epitélio da córnea para cultura do microrganismo ${ }^{(16)}$. Em nosso estudo, o exame citológico revelou vários cistos nas amostras obtidas. Os microrganismos foram observados entre células epiteliais superficiais diferenciando-se de outras células devido ao seu tamanho e à presença de sua parede dupla ${ }^{(17)}$. A CI apresenta vantagens em relação ao raspado porque, além de garantir melhor preservação da estrutura celular, permite obter a localização anatômica e geográfica das células. Se houver positividade na CI, torna-se desnecessário o uso de métodos mais invasivos, como a biópsia ${ }^{(18)}$. É importante ressaltar que a CI analisa as células das camadas mais superficiais do epitélio da córnea, e que nas lesões subepiteliais ou estromais, a captura do organismo será mais difícil ou impossível ${ }^{(10)}$. Estudos futuros são necessários com um maior número de pacientes para se comparar a positividade da CI em relação ao raspado da córnea e outros métodos na detecção de cistos de Acanthamoeba sp.

\section{CONCLUSÕES}

Conclui-se que a citologia de impressão pode ajudar como método laboratorial complementar na detecção de estruturas sugestivas de cistos nos casos de ceratite infecciosa com acometimento superficial da córnea.

\section{AGR ADECIMENTOS}

Ao Prof. Dr. Marcelo Cunha e Profa. Dra. Ana Luisa Höfling-Lima pela ajuda na elaboração do estudo.

\section{ABSTRACT}

To describe three cases of corneal infection due to Acanthamoeba sp in which was possible to detect Acanthamoeba sp cysts by the corneal impression cytology technique. Three patients referred to the External Eye Disease Laboratory in 2004 with superficial corneal alterations were submitted to corneal specimen collection by impression cytology filter paper to investigate the presence of Acanthamoeba sp cysts. Two impression cytology samples were obtained from each patient and were stained by PAS, hematoxylin and Papanicolaou. Routine microbiological investigation and culture were also performed using corneal scraping. Positive culture and impression cytology for Acanthamoeba sp was observed in all patients while smears with Giemsa stain were positive in two. Impression cytology Acanthamoeba sp cysts were observed among sheets of corneal epithelial cells and as isolated cells. Cysts were also found in the superficial epithelium in one of these patients after treatment while corneal scraping did not reveal any cyst. Histopathology revealed cysts in the epithelium and stroma in a transplanted cornea in one of these patients. The first description of impression cytology as a diagnostic method for Acanthamoeba keratitis occurred recently. In this study corneal impression cytology detected Acanthamoeba sp cysts successfully in these patients with only superficial involvement. Impression cytology as a non invasive technique can be used to facilitate early recognition of Acanthamoeba infection playing a useful role in the follow-up of the disease.

Keywords: Acanthamoeba keratitis/diagnosis; Corneal diseases; Cytological techniques; Diagnostic techniques ophthalmological; Case Reports [Publication type]

\section{REFERÊNCIAS}

1. Illingworth CD, Cook SD, Karabatsas CH, Easty DL. Acanthamoeba keratitis: risk factors and outcome. Br J Ophthalmol. 1995;79(12):1078-82. Comment in: Br J Ophthalmol. 1996;80(8):773-4. 
2. Mathers WD. Acanthamoeba: a difficult pathogen to evaluate and treat. Cornea. 2004;23(4):325.

3. Bacon AS, Dart JK, Ficker LA, Matheson MM, Wright P. Acanthamoeba keratitis. The value of early diagnosis. Ophthalmology. 1993;100(8):1238-43.

4. Johns KJ, O’Day DM, Head WS, Neff RJ, Elliott JH. Herpes simplex masquerade syndrome: acanthamoeba keratitis. Curr Eye Res. 1987;6(1):207-12.

5. Ficker LA, Kirkness C, Wright P. Prognosis for keratoplasty in Acanthamoeba keratitis. Ophthalmology. 1993;100(1):105-10.

6. Auran JD, Starr MB, Jakobiec FA. Acanthamoeba keratitis. A review of the literature. Cornea. 1987;6(1):2-26.

7. Sawada Y, Yuan C, Huang AJ. Impression cytology in the diagnosis of acanthamoeba keratitis with surface involvement. Am J Ophthalmol. 2004;137(2): 323-8

8. Barros JN, Mascaro VLD, Gomes JAP, Sousa LB, Hofling-Lima AL. Avaliação da presença de células caliciformes na córnea humana. Arq Bras Oftalmol. 2004;67(1):121-5.

9. Barros JN, Mascaro VLD, Gomes JAP, Freitas D, Hofling-Lima AL Citologia de impressão da superfície ocular: técnica de exame e de coloração. Arq Bras Oftalmol. 2001;64:127-31.

10. Calonge M, Diebold Y, Saez V, Enriquez de Salamanca A, Garcia-Vazquez C, Corrales RM, et al. Impression cytology of the ocular surface: a review. Exp Eye Res. 2004;78(3):457-72
11. Obeid WN, Araujo R, Vieira LA, Machado MAC. Ceratite bilateral por Acanthamoeba - Relato de Caso. Arq Bras Oftalmol. 2003;66(6):876-80.

12. Radford CF, Minassian DC, Dart JK. Acanthamoeba keratitis in England and Wales: incidence, outcome, and risk factors. Br J Ophthalmol. 2002;86(5):536-42. Comment in: Br J Ophthalmol. 2003;87(4):516-7.

13. Mathers WD, Nelson SE, Lane JL, Wilson ME, Allen RC, Folberg R. Confirmation of confocal microscopy diagnosis of Acanthamoeba keratitis using polymerase chain reaction analysis. Arch Ophthalmol. 2000;118(2):178-83.

14. Mathers WD, Sutphin JE, Folberg R, Meier PA, Wenzel RP, Elgin RG. Outbreak of keratitis presumed to be caused by Acanthamoeba. Am J Ophthalmol. 1996;121(2):129-42. Comment in: Am J Ophthalmol. 1996;121(2):207-8.

15. Karayianis SL, Genack LJ, Lundergan MK, Schumann GB. Cytologic diagnosis of acanthamoebic keratitis. Acta Cytol. 1988;32(4):491-4.

16. Florakis GJ, Folberg R, Krachmer JH, Tse DT, Roussel TJ, Vrabec MP. Elevated corneal epithelial lines in Acanthamoeba keratitis. Arch Ophthalmol. 1988;106(9):1202-6.

17. Foronda AS. Infecções por amebas de vida livre. In: Tavares W, Marinho LAC. Rotinas de diagnóstico e tratamento das doenças infecciosas e parasitárias. São Paulo: Atheneu; 2005. p.85.

18. McClellan K, Coster DJ. Acanthamoebic keratitis diagnosed by paracentesis and biopsy and treated with propamidine. Br J Ophthalmol. 1987;71(10):734-6.

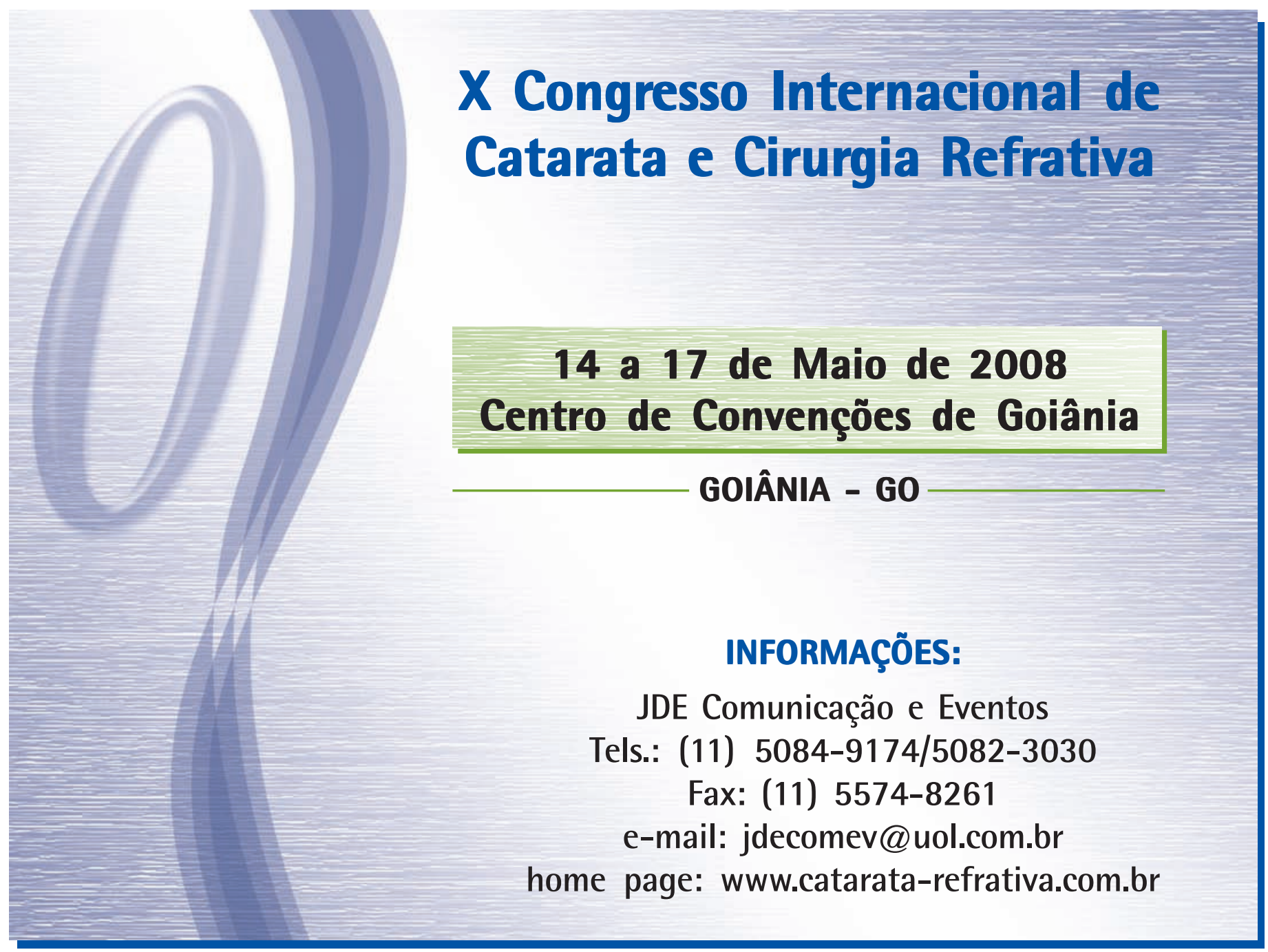

